\title{
Considerations for Choosing the Right Rootstocks ${ }^{1}$
}

William S. Castle and James J. Ferguson ${ }^{2}$

The key to making the best rootstock decision today is to focus on the characteristics of your specific planting site and the known performance of trees on a particular rootstock under those conditions.

Choosing a rootstock is an important decision. It should be carefully considered because the decision is a relatively permanent one and, therefore, has long-term significance. The steps in choosing a rootstock may not always be obvious, but there are several factors that traditionally have been important.

One of the more important factors is your personal experience as well as that of friends, neighbors, and nursery managers. The information you gather from different sources may be conflicting and sometimes confusing, but analyzing and sifting through this material can lead to better rootstock decisions. Some of the other steps and factors involved are described in this publication in a generalized approach to selecting the best rootstocks for your conditions.

Use this fact sheet as as a handy check-off form when preparing to select rootstocks.

\section{Gather the Facts About the Site and Its History}

There is no substitute for having as much factual information as possible. A prominent grower once said that his first step in choosing rootstocks was to read everything he could find. Reading publications like The Proceedings of the Florida State

Horticultural Society is an excellent supplementary activity to all the steps mentioned below.

\section{Know Your Planting Site Characteristics}

\section{Soil Characteristics}

- Soil series (from the County Soil Survey)

- Texture

- Depth to hardpan or clay layer

- Percent organic matter

- Soil pH

- Irrigation water quality (measure electrical conductivity to test for salinity)

- Soil water holding-capacity

1. This document is HS932, one of a series of the Horticultural Sciences Department, Florida Cooperative Extension Service, Institute of Food and Agricultural Sciences, University of Florida. Publication date: June 2003. Please visit the EDIS Web site at http://edis.ifas.ufl.edu.

2. William S. Castle, professor, CREC-Lake Alfred, James J. Ferguson, professor, Horticultural Sciences Department, Cooperative Extension Service, Institute of Food and Agricultural Sciences, University of Florida, Gainesville, 32611. 
- Water drainage

- Soil nutrient status (determined by soil samples)

- Site information from your County Soil Survey. The Soil Survey has some limitations, but you can use it to develop guidelines for bedding procedures for flatwoods groves, to select the best rootstock for your soil conditions and for other related factors.

- Aerial photographs. If you don't have old aerial photos of the site, see if you can obtain them from the Florida Agricultural Statistics Service, your local Natural Resources Conservation Service, or a private vendor. They are quite valuable in showing old ponds and other site variations especially those that existed before planting. The "poor" spots tend to persist in their effects in a grove.

\section{Topography}

Changes in elevation are important for both air (on freeze nights) and water drainage. Images showing elevation changes and other features are available on the internet.

- Visit the Florida Geographic Data Library (FGDL) at the University of Florida (www.fgdl.org) for a wealth of free information including aerial images and the digitized County Soil Surveys.

- Another site is the Florida Department of Environmental Protection Land Boundary Information Systems (LABINS) at www.labins.org. This site has excellent, reasonably current aerial images.

\section{Know Your Objective}

Many decisions are made within the framework of a well-defined goal. Therefore, consider:

- Scion cultivar. Like choosing a rootstock, the cultivar selected represents a choice not often or easily changed after planting. An example of a scion-dependent rootstock choice is the use of Cleopatra mandarin. Evidence from field research suggests that Cleo is an acceptable choice for early-season oranges because of good yield and juice quality; however, the use of Cleo for Valencia budlines is less certain.

- Market. Juice quality may be less important than yield if the fruit is for processing, and this would affect the choice of rootstock. If the fruit is for the fresh market, the influence of the rootstock on external quality may become more important.

- Solid-set or replant sites. Sometimes for replanting, a rootstock different than the one selected for a solid planting is appropriate because of concerns about diseases like Phytophthora foot rot and root rot, and because of tree spacing. When the replant space is small, choosing a rootstock for its vigor rather than for other characteristics becomes more important. Rootstocks of only medium vigor do not compete or grow as well as replants in close spacings.

\section{Know the Rootstocks}

There are two readily available sources of information about rootstocks. Each provides a different perspective. They are:

- Experience. Growers usually feel comfortable planting trees on rootstocks with which they have had positive experiences. The performance boundaries of trees on a particular rootstock are established from years of commercial use. Confidence (and less risk) is derived from that practical experience; however, more risk might be encountered if the decision is made to plant outside those boundaries. For example, it is known that trees on Carrizo do not perform well in calcareous soils. So, while planting trees on Carrizo in soil of $\mathrm{pH} 7.2$ might be an acceptable risk, it would not be an acceptable risk to plant those same trees in a site with plenty of calcareous material present and a soil $\mathrm{pH}$ of 8 . The latter decision exceeds the performance boundary for Carrizo.

\section{- Field Experiments and Research Data.} Rootstock research functions mainly to develop new rootstocks, determine their commercial potential, and to ensure that the capabilities of currently used rootstocks are completely and 
clearly understood. The various field experiments established for this purpose, including those in commercial groves, represent essentially the only source of publicly available data regarding new rootstocks. As a result, they are likely to provide answers for today's important issues, such as tolerance to blight, Diaprepes, etc. It wasn't too many years ago that Swingle citrumelo rootstock was new to the Florida citrus industry. Now, Swingle is a major commercial rootstock, but one with some obvious dents in its armor.

\section{Choose the Rootstock}

The information gathering processes described above provide a sound foundation for this final step; but it is also well to recognize from the outset that all rootstock decisions are tempered by the absence of any perfect choices.

- The relative importance given to individual rootstock traits affects rootstock choice.

- In Florida, rootstock selection is generally based on a combination of concern for productivity and tree survival.

- "Productivity" for juice fruit can be defined as the maximum quantity of juice or soluble solids with the minimum number of risks at the lowest cost. Therefore, priority is normally given to rootstock effects on volume of fruit, but sometimes other factors become limiting and virtually dictate rootstock choices. For example, sweet orange is not usually selected because of susceptibility to foot rot or root rot; sour orange is not chosen because of tristeza; and Carrizo is not a good choice when your irrigation water has high levels of salinity. In contrast, some rootstock characteristics are essentially non-limiting and are, therefore, less important. If trees on a cold tolerant, productive rootstock are susceptible to drought, they can be irrigated.

- Making rootstock selections involves developing a composite assessment of a rootstock based on its individual characteristics, and then choosing the rootstock that best matches your interests and goals. No one rootstock is likely to be entirely satisfactory in any set of circumstances.

- It is often wise to consider using two or three rootstocks especially if those rootstock choices are being matched to variations in the soil and site. If two or more are selected, setting a grove so that trees are planted on alternating rootstocks is not recommended. Rootstocks should be selected to match specific local conditions particularly when planting the highly variable soils found in flatwoods areas. Soil factors and yield are priority determinants. Rootstocks tolerances to wet and dry soil conditions (related, e.g., to depth to clay), and calcareous conditions also must not be ignored.

- Bottom line? Spend most of your time and effort understanding your site and gathering the best information available about rootstock site-specific performance. Ask yourself questions related to the above steps. Then ask why Swingle citrumelo or Carrizo citrange are not acceptable choices. If there are good reasons, then review the rootstocks described on the "rootstock wheel" (Figure 1) which is available from the University of Florida (See Florida Citrus Rootstock Selection Guide, publication SP-248). Finally, there are a number of promising new rootstocks under development that can be included in any discussion of choices.

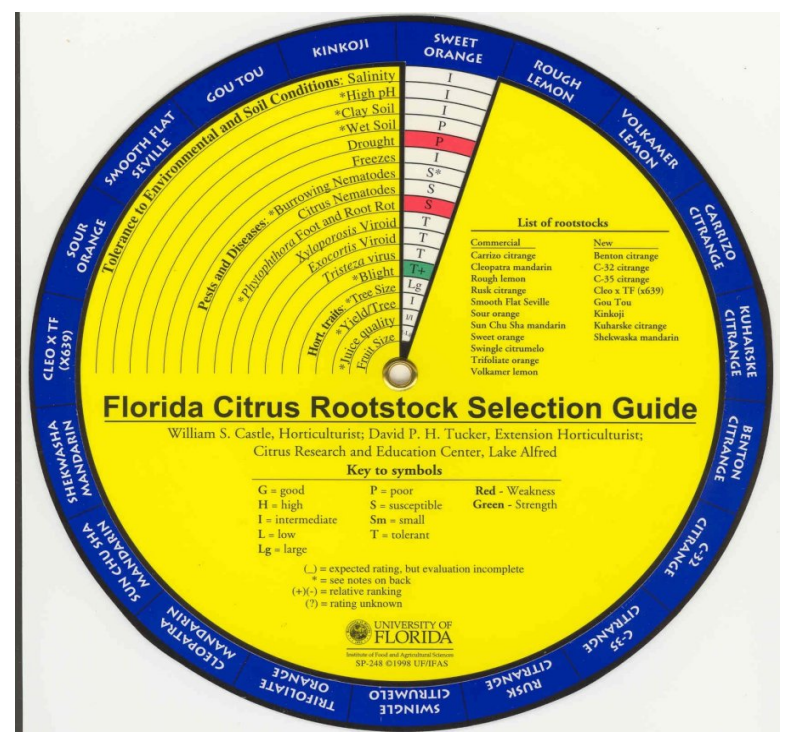

Figure 1. The rootstock wheel available in Florida Citrus Rootstock Selection Guide. 


\section{Your Best Decision?}

Plant your own rootstock trial. It is easy to do, it is easy to manage and it will be your best decision-making tool! 